\title{
Tying Devices to Mitigate Pounding of Adjacent Building Blocks
}

\author{
Mohammed S. Masmoum \\ Civil Engineering Department \\ King Abdulaziz University \\ Jeddah, Saudi Arabia \\ ms.masmoum@gmail.com
}

\author{
Mohammed-Sohaib A. Alama \\ Civil Engineering Department \\ King Abdulaziz University \\ Jeddah, Saudi Arabia \\ sohaib.alama@hotmail.com
}

\begin{abstract}
Adjacent building blocks separated by thermal expansion joints are vulnerable to pounding during earthquakes. The specified Saudi building code minimum separation may be very large and does not necessarily eliminate pounding forces. This research discusses the feasibility of tying the adjacent building blocks with simple devices to mitigate structural pounding when separated by thermal joints. Six and twelve-story moment resistance frames of intermediate ductility were designed for seismic loads of moderate risk. The seismic response was studied for frames with variable separation distances in three cases related to thermal joint, code minimum separation, required separation to eliminate pounding force, and in a fourth case in which the tying device was used along with thermal separation. A linear elastic model was used to model the assigned gap links between the adjacent building blocks. The tying device was modeled with a tension-only hook element. Four normalized earthquake records were used with inelastic-time history analysis to assess the seismic response of the adjacent building blocks. The proposed tying devices reduced successfully the pounding forces by $40 \%$ to $60 \%$ for adjacent building blocks with installed thermal separations. Building damage as observed from damage index and the hysteretic response was not influenced by the pounding force, indicating that the tying may be used on existing buildings with thermal separation as a partial mitigation technique to reduce the pounding hazard in such cases. Further improvement on the tying device will increase the mitigation of the pounding hazard.
\end{abstract}

Keywords-pounding; expansion joint; minimum separation; tying devices

\section{INTRODUCTION}

Saudi Arabian cities exhibited a major development in the recent years and the demand for residential housing and highrise buildings is high. High-rise buildings require sophisticated designs since those flexible structures might include expansion joints that separate them from adjacent rigid structures. This scenario can be idealized by a high-rise tower surrounded by a podium or adjacent to a parking structure. The difference in mass and stiffness between flexible and rigid structures might make them move out-of-phase during strong ground motion events. This movement makes adjacent building blocks prone to pounding hazards. It is thought that tying of adjacent buildings together with a simple tying device allowing thermal movement and preventing out-of-plane movement of the blocks during earthquakes is ought to reduce pounding forces and mitigate seismic hazards. Saudi Building Code [1] requires a minimum separation distance to reduce or eliminate pounding. The minimum separation distance calculation is based on the Square Root Sum of Squares (SRSS) of maximum inelastic drifts of adjacent building blocks. Such separation distance might be wide and requires special architectural treatment to cover the gaps between the adjacent building blocks. So, if the tying device proves feasible in mitigating seismic hazards, it will allow buildings to be placed with narrower separation gaps. The feasibility of tying building blocks with a simple tying device as a means of mitigating pounding and reducing the required separation was validated through the study of the seismic response of adjacent building blocks designed according to $\mathrm{SBC}$ requirements.

During the 1985 Mexico City earthquake, over $40 \%$ of the buildings were severely damaged or collapsed and $15 \%$ of them collapsed due to pounding [2]. In 1989 Loma Prieta earthquake, more than 200 buildings were damaged due to pounding in a radius of $90 \mathrm{~km}$ from the epicenter which indicates that pounding could be catastrophic for cities near or far from active faults [3]. The proposed methods to account for minimum required separation include 1) Absolute Sum of Displacement (ABS), 2) SRSS, and 3) Spectral Difference Method using Double Difference Combination (DDC) rule [48]. SBC 301-2007 did adopt the concept of SRSS rather than DCC, ABS, due to its simplicity, high accuracy, and small differences in the minimum required separation [9-10]. A comparison between these methods concluded that SRSS can be practical and provide the required separation distance [1112]. The need of providing mitigation methods between buildings that do not have enough gap were discussed in [13] by providing a numerical study with different ground motion records to simulate the pounding between light-mass and heavy-mass three-story buildings. The research objective was to measure the efficiency of the available mitigation methods in reducing the required seismic gaps based on time historyanalysis with nonlinear viscoelastic model. It was observed that linking the buildings with springs with stiffness more than $2 \times 10^{4} \mathrm{kN} / \mathrm{m}$ or dampers with damping ratio more than $1 \times 10^{6} \mathrm{~kg} / \mathrm{s}$ reduced the required seismic gap by $85 \%$. This reduction happened because the adjacent buildings were fully connected and vibrated in-phase due to the link installation 
knowing that adjacent buildings are different in dynamical properties and equal in heights. Structural tying of the adjacent building blocks in one complex can make them response as a single structure [14]. The additional relative stiffness due to tying should not create a deficiency on the interacted portions.

The originality of this study is that it proposes tying the adjacent building blocks with simply manufactured steel plates that can be anchored to adjacent buildings blocks and accommodated within the floor finishes using thermal gaps only.

\section{Methodology}

The necessary details for building design and ground motion scaling are explained in [15]. Inelastic time history analysis was used to compute the response of the adjacent building blocks for which the beams were modeled using a single component model with Takeda hysteric behavior selected for the nonlinear rotational hinges at beam ends. In the other-hand, bi-axial interacting hinges were assumed on at the end of the columns. The hinges were defined using automatic hinge generator of SAP2000 [16]. Four cases were considered:

- Case 1: Buildings are separated with thermal expansion joints and without tying devices.

- Case 2: Buildings are separated with code required separation distances and without tying devices.

- Case 3: Buildings are separated with enough distance to totally avoid pounding forces and without tying devices.

- Case 4: Buildings are separated with thermal expansion joints and tied with the proposed tying devices.

Two main response parameters were used to compare the cases in-order to evaluate the feasibility of tying devices in mitigating pounding hazards. The first was the maximum pounding force and the second was the damage state of the buildings. The damage state will be assessed based on inelastic hinge rotations and will be compared with the damage limits as prescribed in [14]. In order to get an overall damage state, a damage index is proposed as per Table I and Figures 1 and 2.

TABLE I. DAMAGE WEIGHT CRITERIA

\begin{tabular}{|c|c|}
\hline Hinge plastic rotation $\boldsymbol{\theta}$ & Index \\
\hline A to B & 0 \\
\hline B to IO & 1 \\
\hline IO to LS & 2 \\
\hline LS to CP & 3 \\
\hline More than CP & 4 \\
\hline \multirow{2}{*}{ Damage index (building) $^{2}$} & $\sum$ (No. Plastic Hinges $\times$ Weighted Index $)$ \\
\cline { 2 - 2 } & No. Plastic Hinges in the Building Members $\times 4$ \\
\hline
\end{tabular}

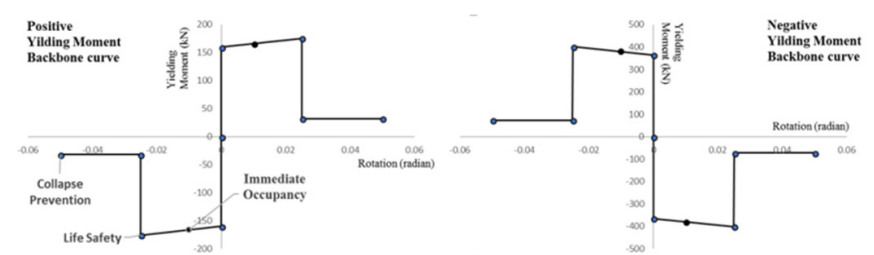

Fig. 1. Beams positive and negative backbone curves for M3 hinges

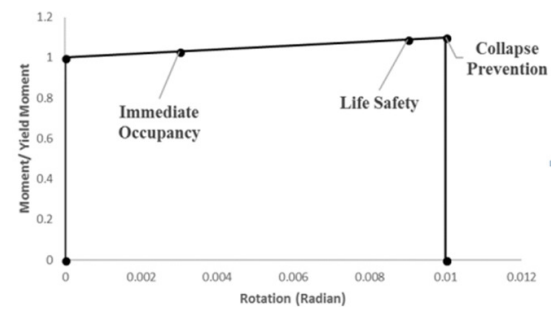

Fig. 2. Column backbone curves for interacting P-M2-M3 hinges

\section{MODELING CONTACT AND TYING OF FRAMES}

Nonlinear contact elements were used at the joint interface between adjacent frames to account for contact force utilizing the gap element in SAP2000. Details are given in [15]. The tying device was modeled using a hook link element in SAP2000. The link connects two joints located around the expansion joint as shown in Figures 3-4. The hook link will simulate tying of adjacent building blocks if the relative displacement exceeds the specified thermal gap opening, in this case $10 \mathrm{~mm}$ for the studied frames.

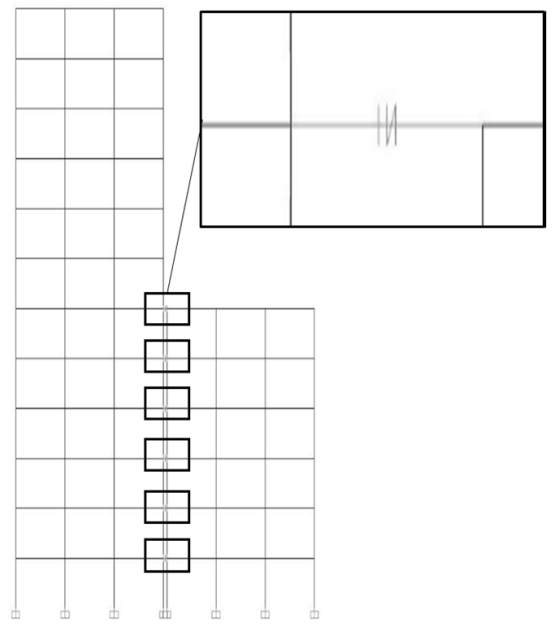

Fig. 3. Hook link assignment in SAP2000

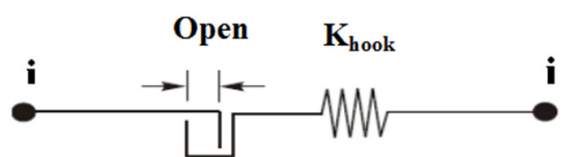

Fig. 4. Representation for the hook link in SAP2000

If the total value of the relative displacement of connected joints exceeds $10 \mathrm{~mm}$, the link will hook the adjacent building blocks. If the total value of the relative displacement lies between 0 and $10 \mathrm{~mm}$, the hook link will not connect the joints as shown in (1). The stiffness of the hook link will be equal to the axial stiffness of the tying devices shown in Figure 5.

$$
f=\left\{\begin{array}{c}
(0) \text { if }(d-\text { open }) \geq 0 \\
K_{\text {hook }}(d-\text { open }) \text { if }(d-\text { open })<0
\end{array}\right.
$$


Figure 5 shows a concept drawing for the proposed tie. The axial stiffness is computed for the rod plates that are expected to be flexible in resisting the tying force as determined in (2).

$$
\mathrm{K}_{\text {hook }}=\frac{\mathrm{E} \times \mathrm{A}}{\mathrm{L}}
$$

where $E$ is the steel modulus of elasticity $\left(200,000 \mathrm{~N} / \mathrm{mm}^{2}\right), A$ and $L$ are the effective cross-sectional area and the length of the rod plates respectively. $K_{\text {hook }}$ is the axial stiffness of the tying device assumed to remain elastic throughout the response.

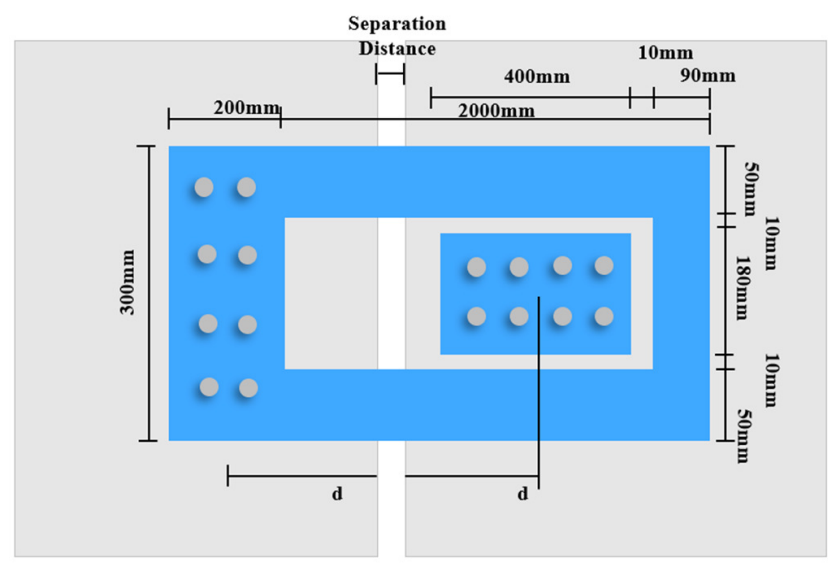

Fig. 5. Conceptual drawing for proposed tying device

\section{RESULTS AND DISCUSSION}

For record RSN0020, building blocks damage states showed acceptable performance as they indicate light damages with plastic hinge rotation less than the life safety limit [14] as shown in Figure 6. The pounding force of Case 1 was $1330 \mathrm{kN}$ while for Case 4 it was $614 \mathrm{kN}$ showing a $54 \%$ reduction when tying devices were used. Also, hysteretic relation for the 6th floor hinges with separations for Cases 2-4 are shown in Figure 7. The maximum plastic hinge rotation indicates a satisfactory performance less than the life safety limit for all cases. Pounding forces did not cause a significant effect on the plastic hinge maximum rotation.

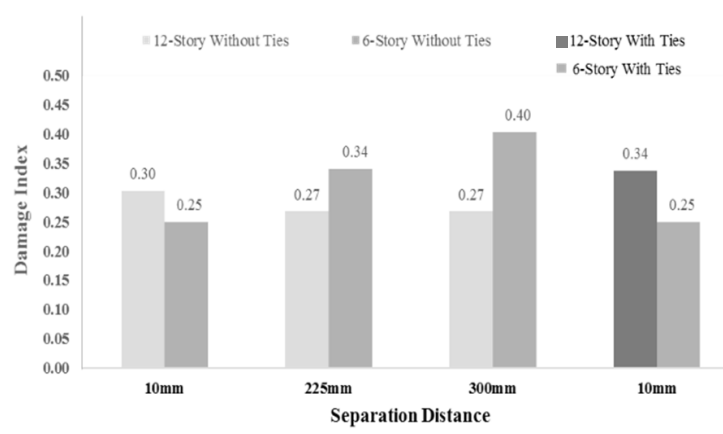

Fig. 6. RSN0020 weighted damage indices for adjacent building blocks with installation of tying devices

For record RSN0169, building blocks damage state showed acceptable performance as the building blocks exhibited light damages with plastic hinge rotation less than the life safety limit [14] as shown in Figure 8. The pounding force of Case 1 was $753 \mathrm{kN}$, but the pounding force of Case 4 was $584 \mathrm{kN}$ showing a $23 \%$ reduction when tying devices were used. The hysteretic relation for the 6th floor hinges with separations for Cases 2-4 are shown in Figure 9.

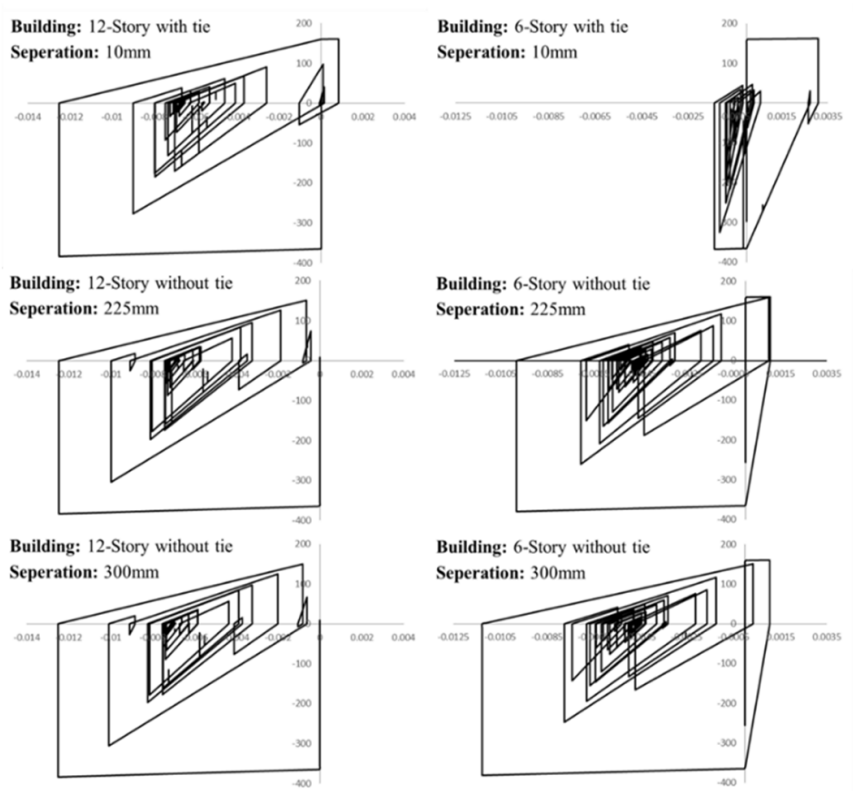

Fig. 7. RSN0020 hysteretic plot for hinges at 6th floor from a 12-story and a 6 -story building block with tying devices installation

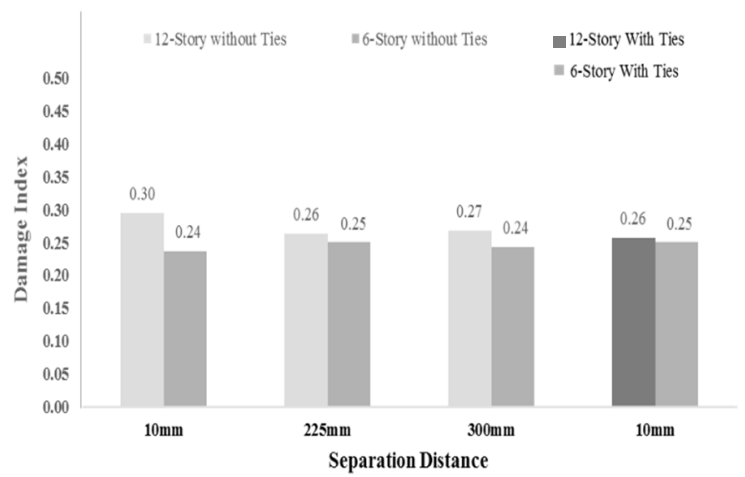

Fig. 8. RSN0020 weighted damage indices for adjacent building blocks with installation of tying devices

The maximum plastic hinge rotation indicates a satisfactory performance less than the life safety limit for all cases. Pounding forces did not cause a significant effect on the plastic hinge maximum rotation. Figure 10 compares the maximum pounding forces in the 6 th floor for adjacent building blocks for the four studied cases. The bar chart demonstrates the computed forces in the gap and hook link with $10 \mathrm{~mm}$ separation distance (Case 4). Minimum required separation distance is highlighted by a straight line. There are two records requiring $300 \mathrm{~mm}$ to avoid pounding and this value is more than the minimum required separations of $225 \mathrm{~mm}$ by the code (Case 2). For full details for the analysis results refer to [17]. 


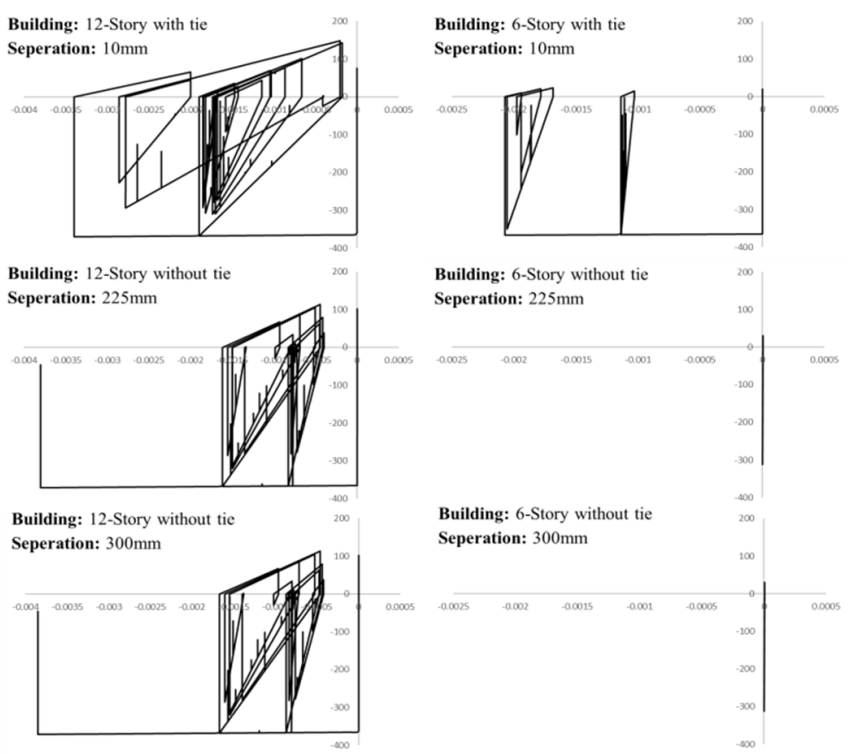

Fig. 9. RSN0169 hysteretic plot for hinges at 6th floor from a 12-story and a 6-story building block with tying devices installation

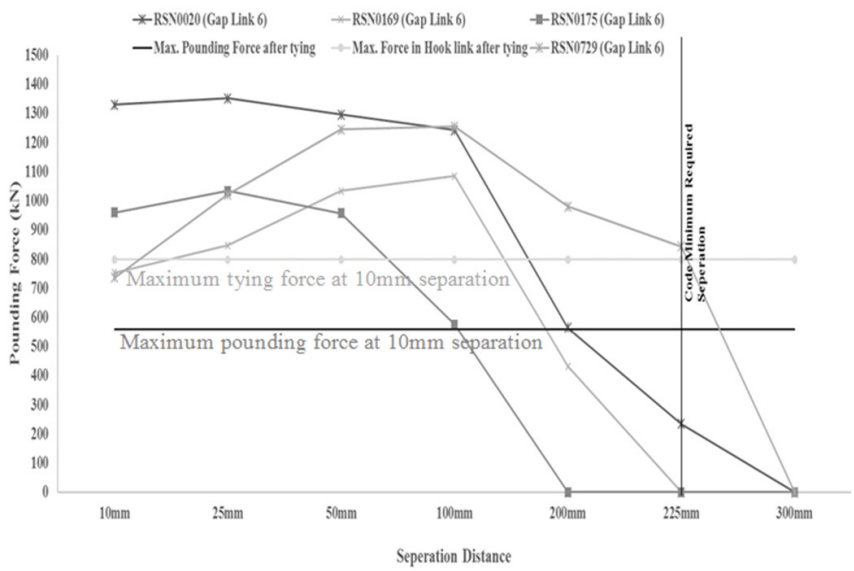

Fig. 10. Comparison between maximum pounding force with tying devices and without tying devices for all the records

\section{CONCLUSION}

Based on the results obtained during the course of the work reported in this paper and earlier works $[15,17]$, the following points can be concluded:

- The proposed tying devices successfully reduced pounding forces from $40 \%$ to $60 \%$ for adjacent building blocks with $10 \mathrm{~mm}$ separation comparing to adjacent building blocks without tying devices. Building damage as observed from damage index and hysteretic response was not influenced by pounding force in either case. This indicates that tying can be used on existing buildings with thermal separation as a partial mitigation technique to reduce pounding hazards. Further improvement on the tying device will increase the mitigation of the pounding hazard.

- Tying devices can be used on buildings with normal expansion joints and mitigate the pounding effect on similar or better level than seismic joints with code minimum required separations. This was clearly shown as the maximum pounding force reduced from $1330 \mathrm{kN}$ for code separation to $614 \mathrm{kN}$ using the tying device with thermal separation only. The observed building damage from the damage index and hysteretic response was not influenced by the pounding force in either case.

- The effect of pounding on the hysteretic damage of the building blocks can be better assessed by comparing the enclosed hysteretic area of the plastic hinges of the structure in addition to the maximum plastic rotation before and after the installation of tying devices.

- Tying devices could be designed based on nonlinear analysis using the methodology used in this work.

- It was observed that the pounding force will not be more than $20 \%$ of the adjacent building blocks base shear summation. This approximation with the results from further parametric studies can be used to estimate the maximum tying force for design purposes.

- The equivalent spring stiffness based on floor lateral displacement can be assumed as gap link stiffness to give a converged solution. If the integration did not converge, the stiffness value might need a further multiplicand to reach a converged solution.

- It was observed that pounding forces could not be eliminated by applying the code minimum separation distance of $225 \mathrm{~mm}$. This was especially observed when using nonlinear response history analysis for sites that are characterized with liquefiable soils.

\section{REFERENCES}

11] SBC Committee 301, Structural - loading and forces, Saudi Building Code National Committee, 2007

[2] E. Rosenblueth, R. Meli, "The 19875 earthquake: Causes and effects in Mexico City”, Concrete International, Vol. 8, pp. 23-34, 1986

[3] K. Kasai, B. F. Maison, "Building the 1989 pounding damage during Loma Prieta earthquake”, Engineering Structures, Vol. 19, No. 3, pp. 195-207, 1997

[4] V. Jeng, K. Kasai, B. F. Maison, "A spectral difference method to estimate building separations to avoid pounding", Earthquake Spectra, Vol. 8, No. 2, pp. 201-223, 1992

[5] J. Penzien, "Evaluation of building separation distance required to prevent pounding during strong earthquakes", Earthquake Engineering \& Structural Dynamics, Vol. 26, No. 8, pp. 849-858, 1997

[6] J. H. Lin, "Separation distance to avoid sesmic pounding of adjacent buildings", Earthquake Engineering and Structural Dynamics, Vol. 26, pp. 395-403, 1997

[7] R. E. Valles, A. M. Reinhorn, Evaluation, prevention and mitigation of pounding effects in building structures, National Center for Earthquake Engineering Research, 1997

[8] H. P. Hong, S. S. Wang, P. Hong, "Critical building separation distance in reducing pounding risk under earthquake excitation", Structural Safety, Vol. 25, No. 3, pp. 287-303, 2003

[9] D. Lopez-Garcia, T. T. Soong, "Evaluation of current criteria in predicting the separation necessary to prevent seismic pounding between nonlinear hysteretic structural systems", Engineering Structures, Vol. 31, No. 5, pp. 1217-1229, 2009

[10] R. Jankowski, S. Mahmoud, Earthquake-induced structural pounding, Springer International Publishing, 2015 
[11] M. J. Favvata, "Minimum required separation gap for adjacent RC frames with potential inter-story seismic pounding", Engineering Structures, Vol. 152, pp. 643-659, 2017

[12] M. Isteita, K. Porter, "Safe distance between adjacent buildings to avoid pounding in earthquakes", 16th World Conference on Earthquake Engineering, Santiago Chile, January 9-13, 2017

[13] R. Jankowski, S. Mahmoud, "Mitigation of pounding effects", in: Earthquake-Induced Structural Pounding, Springer International Publishing, pp. 103-132, 2015

[14] ASCE/SEI Committee 7, Minimum design loads for buildings and other structures", American Society of Civil Engineers, 2010

[15] M. Masmoum, S. Alama, "Required seperation to mitigate pounding of adjacent building blocks", Engineering, Technology \& Applied Science Research, Vol. 8, No. 6, pp. 3565-3569, 2018

[16] Computers and Structures Inc., CSI Analysis Reference Manual for SAP2000, Etabs, Safe, and CSI Bridge. Computers and Structures Inc., 2016

[17] M. Masmoum, Buildings pounding mitigation using tying device, MSc Thesis, King Abdulaziz University, 2019 